University of Nebraska - Lincoln

DigitalCommons@University of Nebraska - Lincoln

10-1993

\title{
Developmental Niche Structure in the Gregarine Assemblage Parasitizing Tenebrio molitor
}

Richard E. Clopton

Peru State College, RClopton@peru.edu

John J. Janovy Jr.

University of Nebraska - Lincoln, jjanovy1@unl.edu

Follow this and additional works at: https://digitalcommons.unl.edu/bioscijanovy

Part of the Parasitology Commons

Clopton, Richard E. and Janovy, John J. Jr., "Developmental Niche Structure in the Gregarine Assemblage Parasitizing Tenebrio molitor" (1993). John Janovy Publications. 10.

https://digitalcommons.unl.edu/bioscijanovy/10

This Article is brought to you for free and open access by the Papers in the Biological Sciences at DigitalCommons@University of Nebraska - Lincoln. It has been accepted for inclusion in John Janovy Publications by an authorized administrator of DigitalCommons@University of Nebraska - Lincoln. 


\title{
DEVELOPMENTAL NICHE STRUCTURE IN THE GREGARINE ASSEMBLAGE PARASITIZING TENEBRIO MOLITOR
}

\author{
R. E. Clopton and J. Janovy, Jr. \\ School of Biological Sciences, University of Nebraska-Lincoln, Lincoln, Nebraska 68588-0118
}

\begin{abstract}
The exogenous developmental niche spaces of Gregarina cuneata and Gregarina polymorpha, parasites restricted to larval Tenebrio molitor, and Gregarina niphandrodes, a parasite restricted to adult $T$. molitor, were determined along temperature and humidity axes and associated with parasite niche space on the host resource axis. Gregarine gametocysts were incubated at controlled humidity $(0,10$, and $20 \mathrm{~mm} \mathrm{Hg}$ vapor pressure deficit) at 20,25,30, and $35 \mathrm{C}$ to determine the environmental limits to survival and sporulation. Although the environmental conditions that permit gametocyst development overlap, the gregarine parasite restricted to adult $T$. molitor utilizes a subset of sporulation and survival conditions that is incompatible with the developmental needs of the gregarines restricted to larval $T$. molitor. Likewise, the gregarine parasites that are restricted to larval $T$. molitor survive and sporulate under a subset of environmental conditions that are incompatible with the developmental needs of the gregarine restricted to adult $T$. molitor. Gregarina niphandrodes survived and sporulated under extended environmental conditions characterized by lower humidity and temperature. In contrast, $G$. cuneata and $G$. polymorpha survived and sporulated under extended environmental conditions at the upper end of the temperature scale. The pattern of interspecific variation in the environmental tolerances of the exogenous gregarine stages is analogous to the pattern of interspecific variation in host stadium specificity observed in the corresponding endogenous gregarine stages.
\end{abstract}

Parasites that form stable systems with only 1 or a very few host species are said to be host specific (Kennedy, 1975). A high degree of host specificity can be inferred from taxonomic literature concerning the genus Gregarina. The strength of this inference is reflected in the most recent review of Septatorina in which Levine (1979) noted the apparent homoxenous nature of the species within the genus as a justification for the use of host species as a taxonomic character. However, host specificity in the eugregarines seldom has been defined experimentally. Patil et al. (1985) addressed the question of eugregarine host specificity using gregarines of 9 species of Stylocephalus, Xiphocephalus, and Cryptocephalus in cross-infection experiments with 8 species of tenebrionid beetles. Although exsporulation was reported in 5 heterologous host-parasite combinations, parasite establishment and growth were observed only in homologous combinations.

Extreme host specificity within the eugregarine parasites of insects may extend to ontogenetic stages of a single host species. Clopton et al. (1992) demonstrated stadium specificity in the gregarine assemblage parasitizing Tenebrio molitor using controlled, reciprocal, experimental cross-infections. In this case, adult and larval beetles constituted different hosts and thus different habi-

Received 14 January 1993; revised 4 May 1993; accepted 20 May 1993. tats, at least in laboratory colonies. Host stadium specificity in the gregarine assemblage parasitizing $T$. molitor is believed to be mediated by the interaction of a potential host and the sporozoite; that is, extreme host specificity is a functional feature of endogenous parasitic stages. Other indications of extreme host specificity also may be present in the exogenous stages of the gregarine life cycle. In a complex life cycle, the suite of characteristics that delimits niche space may vary among ontogenetic stages.

Most gregarines utilize a direct life cycle. Briefly, infective oocysts are consumed and exsporulate in the insect gut. Free sporozoites migrate to the mid-gut epithelium where they undergo first an intracellular and then an extracellular growth phase. Gamonts form reproductive associations and, when mature, undergo syzygy to form single gametocysts that are passed to the environment in the feces. Sexual recombination and asexual multiplication are completed in the exogenous gametocyst. Mature gametocysts sporulate in the environment to release oocysts and continue the infective cycle. Allegre (1948) and Levine (1985) provided more complete reviews of the gregarine life cycle.

The gregarines infecting Tenebrio molitor constitute a feasible experimental system for gametocyst studies because the gametocysts of these species are readily separated using structural features. Lipa (1967) described the gametocysts of Gregarina cuneata as follows, "Cysts oval up to 600 micrometers in diameter"; however, his ac- 
companying figures clearly illustrate Gregarina polymorpha. In single parasite species infections, the gametocysts of $G$. polymorpha are ovoid and approximately $400 \mu \mathrm{m}$ in diameter, whereas the gametocysts of $G$. cuneata are round and approximately $245 \mu \mathrm{m}$ in diameter (Reichenow and Wülker, 1929; Mackinnon and Hawes, 1961). In general, the gametocysts of $G$. polymorpha appear singly, whereas the gametocysts of $\mathrm{G}$. $\mathrm{Cu}$ neat $a$ are shed in grapelike clusters.

Ambient temperature has been identified as a factor influencing the rate of gregarine gametocyst development (Patil et al., 1983). Anecdotal observations suggest that in addition to temperature, water balance is a primary abiotic factor limiting gametocyst maturation and development. The environmental requirements for gametocyst development may differ among species in the gregarine assemblage parasitizing $T$. moli$t o r$, and the nature of this variation may reflect host specificity. This study explores these possibilities by quantifying the effects of temperature and humidity, over a controlled range, on gametocyst development in the gregarine assemblage parasitizing $T$. molitor.

\section{MATERIALS AND METHODS}

\section{Gametocyst collection and parasite maintenance}

Tenebrio molitor colonies were maintained on wheat bran and potato slices in $30.9-\mathrm{L}$ plastic boxes. The wheat bran substrate was covered with burlap that was moistened daily. Three gregarine species were manipulated: $G$. cuneata and $G$. polymorpha from $T$. molitor larvae, and Gregarina niphandrodes from T. molitor adults. Multiple gregarine species infections are common in larval $T$. molitor. The gametocysts from multiple parasite species infections were sorted on the basis of gametocyst structure. Gametocysts were collected from both adult and larval $T$. molitor by placing 500 3,000 insects in a plastic box with moist paper towels overnight. Feces were examined the next morning. Gametocysts were freed by softening frass in basic saline solution, sorted by parasite species, surface sterilized in $0.01 \%$ neutral-buffered formalin, and pipetted in lots of 10 gametocysts to circles of black construction paper (6 mm diameter). The black background improved visibility of oocyst chains. Gametocysts were kept in separate filter paper-lined petri dishes according to parasite species and incubated at controlled temperature and humidity.

\section{Temperature and humidity control}

Temperature and humidity were controlled using a series of Plexiglas humidity chambers inside a FREAS 815 low temperature incubator. Constant humidity was established and maintained using a modified apparatus similar to that of Perring et al. (1984). Aquarium pumps provided 2 air flow lines. One line bubbled through distilled water, producing a "wet" air stream; the other line passed through a series of silica gel desiccating columns, producing a "dry" air stream. Experimental humidities were established by regulating the flow of the wet and dry air streams into each humidity chamber using a simple gang-valve system. Temperature and humidity within each chamber were monitored with a solid-state digital hygrometer/thermometer.

Humidities reported are vapor pressure deficits measured in millimeters of mercury (VPD). VPD is the difference between the actual vapor pressure of water in air and the saturation vapor pressure of water in air at the same temperature (Platt and Griffiths, 1964). Experiments were conducted at 0 (saturated $\mathrm{H}_{2} \mathrm{O}$ vapor), 10 (median $\mathrm{H}_{2} \mathrm{O}$ vapor), and 20 (low $\mathrm{H}_{2} \mathrm{O}$ vapor) $\mathrm{mm} \mathrm{Hg}$ VPD at 20,25,30, and $35 \mathrm{C}$. Low $\mathrm{H}_{2} \mathrm{O}$ vapor tests at $20 \mathrm{C}$ were conducted at $17.5 \mathrm{~mm} \mathrm{Hg}$, the maximum aqueous VPD possible at that temperature (Anonymous, 1986).

\section{Experimental protocol}

The experimental design was devised to investigate 2 development processes in the exogenous gregarine gametocyst: survival and sporulation (oocyst chain extrusion). Sporulation at any given temperature/humidity combination was tested with a controlled incubation bioassay. Survival was tested using a reversal bioassay in which gametocysts were incubated at the experimental temperature/humidity for the duration of normal development, transferred to a high humidity incubation chamber, and observed for subsequent sporulation.

In each experimental replication, 60 gametocysts from each parasite species were incubated at controlled temperature and humidity for $100 \mathrm{hr}$. The condition of each gametocyst (sporulated, stable, or desiccated) was observed and recorded every $25 \mathrm{hr}$. After $50 \mathrm{hr}$ of incubation (normal development time for sporulation [Clopton et al., 1991]), the reversal bioassay groups were transferred to the 0 VPD chamber. All gametocysts were removed and examined every $25 \mathrm{hr}$ during the 100-hr experiment.

The data are derived from 3 replications for each of 12 experimental temperature/humidity combinations. A total of 2,160 gametocysts ( 720 gametocysts/parasite species) were manipulated.

\section{RESULTS}

The percentages of gametocysts of $G$. niphandrodes, G. cuneata, and G. polymorpha sporulating under various temperatures and humidities are depicted in Figures 1-3. In all parasite species tested, temperature and humidity directly affected gametocyst development and extreme temperature or VPD limited gametocyst sporulation. Gametocyst sporulation rates in all 3 gregarine species were greatest at high humidity ( $0 \mathrm{~mm} \mathrm{Hg}$ VPD). Low humidity $(20 \mathrm{~mm} \mathrm{Hg}$ VPD) generally depressed gametocyst sporulation in $G$. niphandrodes and precluded sporulation in $G$. cuneata and $G$. polymorpha. Low humidity in combination with low temperature ( 20 C) also precluded gametocyst sporulation in $G$. 
niphandrodes. High temperature (35 C) precluded gametocyst sporulation in $G$. niphandrodes at median humidity (10 $\mathrm{mm} \mathrm{Hg} \mathrm{VPD)} \mathrm{and} \mathrm{in} \mathrm{all} 3$ species at low humidity. Gametocysts of $G$. $c u$ neata and $G$. polymorpha were more tolerant of high temperature at high humidity than gametocysts of $G$. niphandrodes $(63,66$, and $3 \%$ sporulation, respectively); however, gametocyst sporulation in $G$. cuneata and G. polymorpha was depressed at high temperature and median humidity. Low temperature precluded sporulation in $G$. cuneata and G. polymorpha at all humidities. Gametocysts of $G$. niphandrodes sporulated at low temperature only in combination with median or high humidity.

The percentage of gametocyst survival for $G$. niphandrodes, G. cuneata, and G. polymorpha, measured by sporulation under high humidity after initial incubation at various humidities and temperatures, is depicted in Figures 4-6. Gametocyst survival in all 3 gregarine species was greatest after incubation at median or high humidity and generally depressed under low humidity. Although gametocyst survival in $\mathrm{G}$. $\mathrm{cu}$ neata and $G$. polymorpha was depressed by high temperature incubation, survival was not precluded. The gametocysts of these species were more tolerant of high temperature incubation at all humidities than gametocysts of $G$. niphandrodes. Incubation at low or median humidity in combination with high temperature precluded G. niphandrodes gametocyst survival. Incubation under low humidity at $20 \mathrm{C}$ and $25 \mathrm{C}$ precluded survival in G. cuneata and G. polymorpha. Survival was precluded or dramatically reduced in G. cuneata and G. polymorpha by low temperature incubation under all humidities tested.

Although these data are useful to determine the optimal temperature and humidity conditions for gametocyst development in $G$. niphandrodes, G. cuneata, and G. polymorpha, they are most informative when used to compare absolute, rather than relative, responses among parasite species.

Figure 7 depicts the environmental conditions that permit sporulation of the gametocysts of all 3 parasite species. Gregarina niphandrodes, the parasite of adult $T$. molitor, sporulated under drier conditions at 25 and $30 \mathrm{C}$. Its tolerance to low humidity decreased at higher or lower temperatures. Gregarina cuneata and G. polymorpha, the parasites of larval $T$. molitor, sporulated between 25 and $35 \mathrm{C}$. Under no condition tested did they sporulate under vapor pressure deficits in excess of $10 \mathrm{~mm} \mathrm{Hg}$.

Figure 8 depicts the environmental conditions that permit survival of the gametocysts of all 3 species. Gregarina niphandrodes gametocysts could survive at humidities too low to facilitate sporulation: their survival tolerance to high VPD extended beyond sporulation limits at lower temperatures. Likewise, G. cuneata and G. polymorpha gametocysts survived at humidities that were too low to facilitate sporulation. In contrast to the gametocysts of $G$. niphandrodes, the survival tolerance of $G$. cuneata and $G$. polymorpha gametocysts to high VPD was extended beyond sporulation limits at higher temperatures. The set of environmental conditions that permit survival are similar to, but wider than, the environmental conditions that permit sporulation.

\section{DISCUSSION}

Ferro and Chapman (1979) demonstrated that some measure of the effects of vapor flux, i.e., the exchange of water vapor between an animal and the environment, is required to establish humidity as a causal factor in the response of an organism to environmental changes. Vapor pressure deficit, rather than relative humidity, was chosen as the humidity measure for this study. VPD is a temperature-independent measure of the "drying power of the air" (a phenomenon of biological interest), and it measures the potential for water vapor exchange between an organism and the environment (Ferro and Chapman, 1979; Perring et al., 1984). VPD is the difference between the actual vapor pressure of water in air and the saturation vapor pressure of water in air at the same temperature (Platt and Griffiths, 1964). As VPD increases, the drying power of the air increases; that is, vapor pressure deficit and humidity are inversely related. In contrast, relative humidity is a function of temperature; constant relative humidity does not provide a directly comparable measure of the biological effects of ambient humidity over a temperature gradient. Thus the advantage of VPD over relative humidity is that biologically meaningful constant humidities can be measured over a temperature gradient in an effort to demonstrate the causal interactions of temperature and humidity on biological processes.

The sporulation and survival responses of $G$. niphandrodes, G. cuneata, and G. polymorpha gametocysts were directly affected by both temperature and humidity. For all 3 species, extreme 

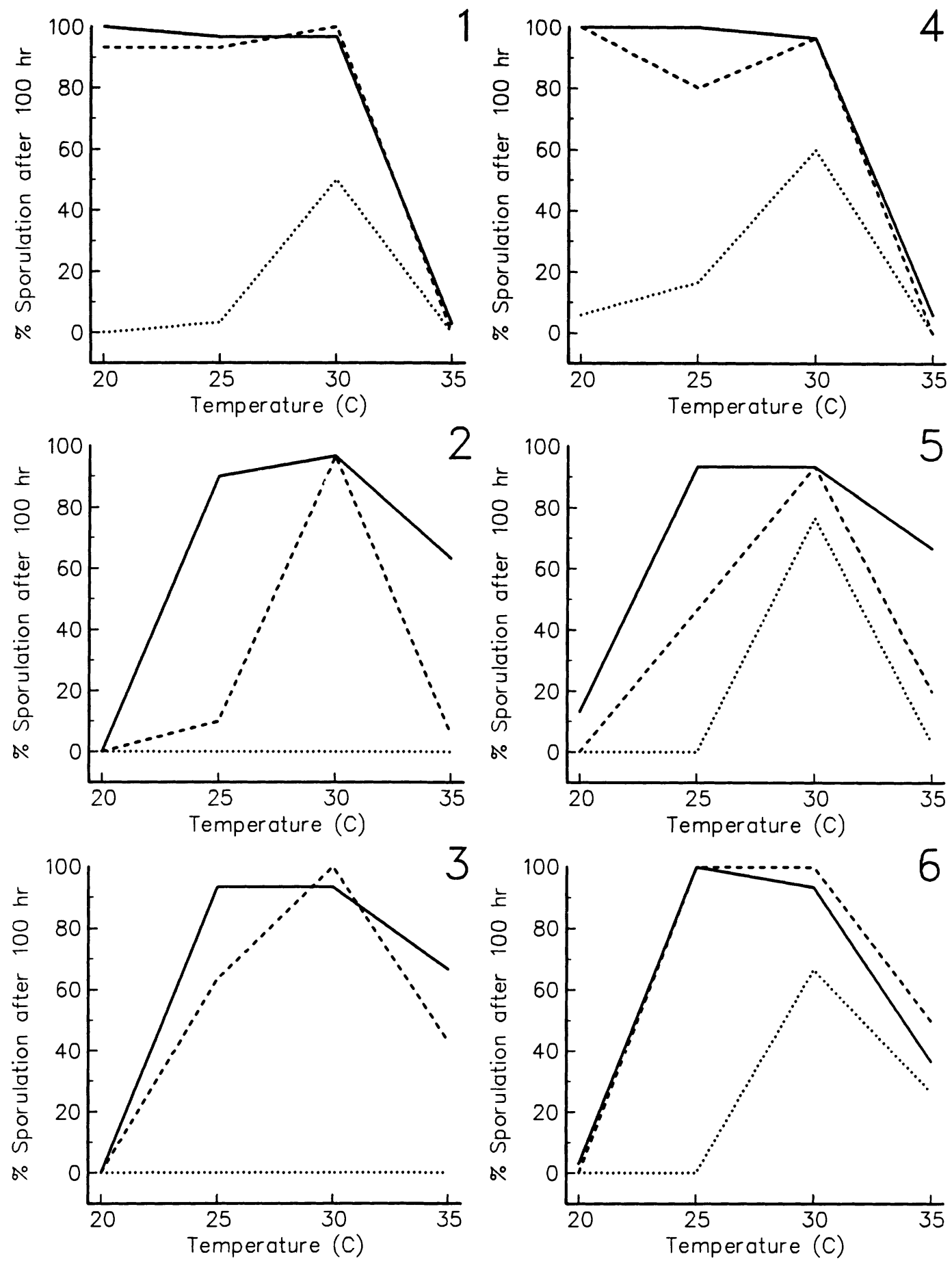

$0 \mathrm{~mm} \mathrm{Hg}$ VPD -......... $10 \mathrm{~mm} \mathrm{Hg} \mathrm{VPD}$

$20 \mathrm{~mm} \mathrm{Hg}$ VPD

Figures 1-6. Gametocyst sporulation (1-3) and survival (4-6) as functions of temperature (20, 25, 30, 35 C) and humidity $(0,10,20 \mathrm{~mm} \mathrm{Hg}$ vapor pressure deficit [VPD]) for 3 species of Gregarina. 1. Gregarina niphandrodes. 2. Gregarina cuneata. 3. Gregarina polymorpha. 4. Gregarina niphandrodes. 5. Gregarina cuneata. 6. Gregarina polymorpha. 

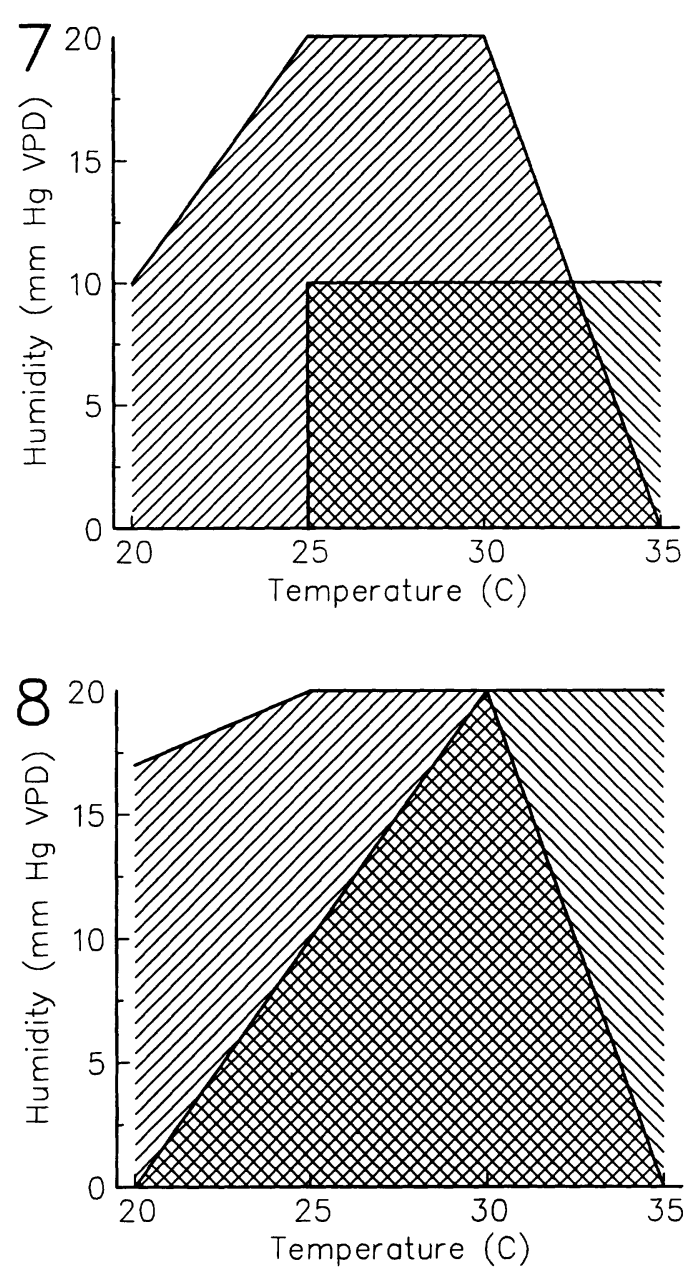

Figures 7, 8. Relative gametocyst sporulation and survival as functions of temperature $(20,25,30,35 \mathrm{C})$ and humidity $(0,10,20 \mathrm{~mm} \mathrm{Hg}$ vapor pressure deficit [VPD]) for 3 species of Gregarina. Gregarina niphandrodes, //////; Gregarina cuneata and Gregarina polymorpha, $\ \backslash \backslash \backslash$; Gregarina niphandrodes, Gregarina cuneata, and Gregarina polymorpha, $\infty \infty \infty \times$. 7. Gametocyst sporulation. 8. Gametocyst survival.

temperature or humidity could act as a single limiting factor for gametocyst development. The temperature results are similar to those obtained by Patil et al. (1983) for Gregarina bidari and Gregarina opatroidea gametocysts. However, the effect of subsaturation humidity, alone or in combination with temperature, on gametocyst development in these latter species is unknown. In comparison to the developmental temperature ranges reported here for gametocysts of Gregarina species, Patil et al. (1983) reported broader developmental temperature ranges for the gametocysts of Stylocephalus depressicus,
Stylocephalus pseudoblapsis, Stylocephalus punctulatus, Xiphocephalus gonocephali, and Xiphocephalus reitterae. Narrower developmental temperature ranges were reported for Cystocephalus rhytonotus, Cystocephalus devdhari, and Leidyana gnynanagangai. In all known cases, less variation in developmental temperature tolerance has been observed for congeneric species than has been observed between species of different genera. That is, gregarine gametocyst developmental temperature tolerance appears to vary in a systematic way consistent with currently understood taxonomic relationships.

The absolute sporulation and survival responses of $G$. niphandrodes, $G$. cuneata, and $G$. polymorpha gametocysts indicate a shared set of environmental conditions for sporulation and survival. Although the environmental conditions that permit gametocyst development overlap, the gregarine parasite restricted to adult $T$. molitor utilizes a subset of sporulation and survival conditions that is incompatible with the developmental requirements of the gregarines restricted to larval $T$. molitor. Likewise, the gregarine parasites that are restricted to larval $T$. molitor survive and sporulate under a subset of environmental conditions that are incompatible with the developmental requirements of the gregarine restricted to adult $T$. molitor. Gregarina niphandrodes survived and sporulated under extended environmental conditions characterized by lower humidity and temperature. In contrast, $G$. cuneata and $G$. polymorpha survived and sporulated under extended environmental conditions at the upper end of the temperature scale. Thus, the pattern of interspecific variation in the environmental tolerances of the exogenous gregarine stages is analogous to the pattern of interspecific variation in host stadium specificity observed in the corresponding endogenous life cycle stages.

Functional survival and sporulation responses can delimit the niche breadths of $G$. niphandrodes, G. cuneata, and G. polymorpha in Hutchinsonian space. Figure 9 depicts the developmental niche areas for the gametocysts of all 3 gregarine species, using humidity (VPD) as the resource set at a constant temperature of $25 \mathrm{C}$. Dispersal and transmission of gregarine oocysts are functions of the overlap of the niche spaces of host and parasite. Although dispersal is a passive function of host movement and behavior, transmission is dependent upon both host feeding and suitable environmental conditions for 


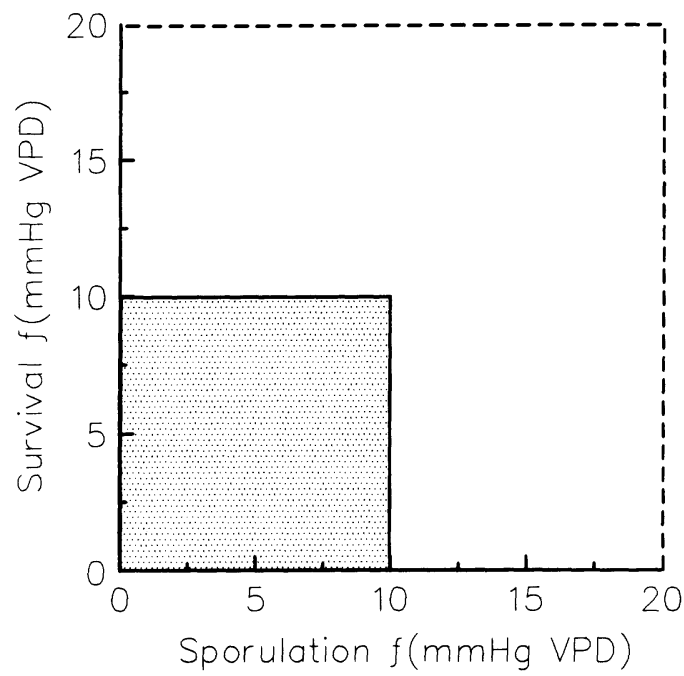

FIGURE 9. Gametocyst developmental niche area, as a function of survival and development on the resource set humidity $(\mathrm{mm} \mathrm{Hg}$ vapor pressure deficit [VPD]) at $25 \mathrm{C}$, for 3 species of Gregarina. Gregarina niphandrodes, ---; Gregarina cuneata and Gregarina polymorpha, _-; overlap of Gregarina niphandrodes with Gregarina cuneata and Gregarina polymorpha, $\mathbf{\square}$

gametocyst survival and sporulation. Thus, dispersal and transmission in a variable environment are limited by the survival and sporulation tolerances of the gametocyst. In effect, the habitat is partitioned among gregarine species by its differential suitability for gametocyst development. The difference among the developmental niche areas of the exogenous stages of $G$. niphandrodes, G. cuneata, and G. polymorpha (Fig. 9) indicates the potential for habitat partitioning among these 2 groups under various humidities at $25 \mathrm{C}$.

Gregarine gametocyst development is also subject to temperature influence and restriction. The temperature and humidity restrictions on the survival and sporulation of gregarine gametocysts can be represented in 3-dimensional Hutchinsonian niche space as a series of humidity-based developmental niche areas distributed along a temperature gradient. The enclosed developmental niche volume describes the conditions that will permit dispersal in the gametocyst stage (and subsequent transmission) as limited by temperature and humidity. The nature of shared and expanded developmental niches is apparent when the developmental niche volumes for the gametocysts of all 3 gregarine species are drawn in concomitant space (Fig. 10). All 3 parasite species share a common development niche volume congruent with the preferred tempera-

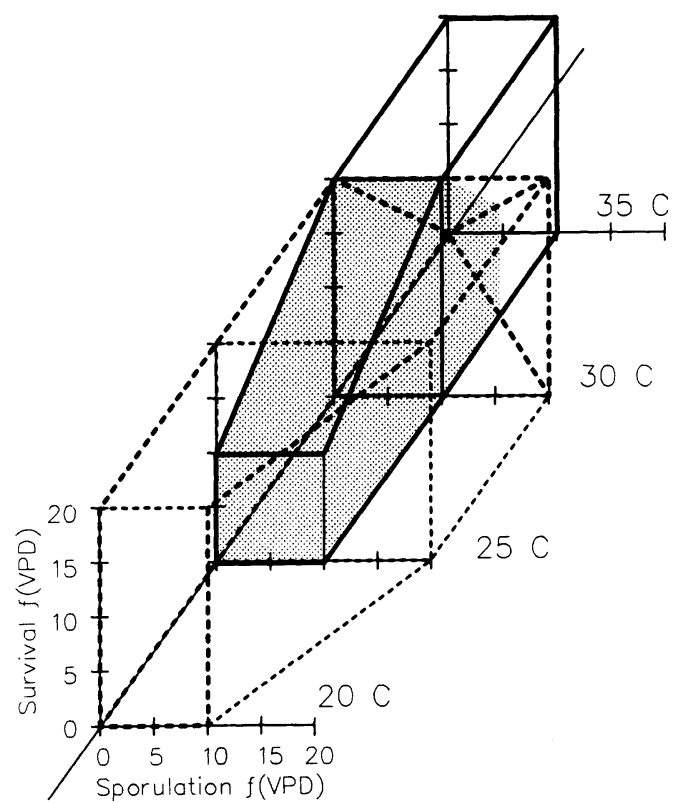

Figure 10. Gametocyst developmental niche volume, as a function of survival and development on the resource set humidity (mm $\mathrm{Hg}$ Vapor pressure deficit [VPD]) between 20 and $35 \mathrm{C}$, for 3 species of Gregarina. Gregarina niphandrodes, - -; Gregarina cuneata and Gregarina polymorpha, __; overlap of Gregarina niphandrodes with Gregarina cuneata and Gregarina polymorpha,

ture range overlap of larval and adult $T$. molitor at all humidities (Mellanby, 1932; Howard, 1955; Punzo and Mutchmor, 1978, 1980). However, $G$. cuneata and $G$. polymorpha also share a development niche volume incompatible with $G$. niphandrodes. This volume is a function of the increased survival and sporulation tolerances of these parasites to higher temperatures and corresponds to the expanded thermal niche of larval T. molitor (especially younger larval instars) (Buxton, 1930; Pielou and Gunn, 1940; Punzo and Mutchmor, 1978, 1980). Likewise, G. niphandrodes retains a development niche volume incompatible with G. cuneata and G. polymor$p h a$. This volume is a function of the higher overall survival and sporulation tolerances of this parasite to lower humidities between 20 and 30 $\mathrm{C}$ and corresponds to the expanded niche of adult $T$. molitor at low temperature and humidity (Mellanby, 1932; Pielou and Gunn, 1940; Howard, 1955; Punzo and Mutchmor, 1978, 1980; Punzo and Huff, 1989).

The observed conditions for gametocyst development correspond to the niche volumes of host stadia. The niche of $T$. molitor, as defined 
by temperature and humidity, is subdivided into an intermediate area that supports all stadia, an area at upper temperatures that supports larval stadia but not the adult stadium, and an area at lower temperature and humidity that supports the adult stadium but not larval stadia. Low humidity tolerance is a function of the production of metabolic water from ingested food and, when provided with a sufficient food supply, adult and larval $T$. molitor can survive under relatively xeric conditions (Buxton, 1930, 1932). Temperature tolerance in late larval instars and adult stages is mediated by the potential for evaporative cooling (Buxton, 1930; Mellanby, 1932; Pielou and Gunn, 1940). The potential for evaporative cooling, as a function of VPD, does not satisfy the requirements of larger late instar larvae and adults at high temperatures and humidities (Mellanby, 1932; Punzo and Mutchmor, 1978, 1980; Punzo and Huff, 1989). This limitation becomes pronounced with decreasing surface area : volume ratios. Conversely, low temperature and humidity markedly increase the mortality of smaller early instar larvae (Punzo and Mutchmor, 1980). This phenomenon may be a result of reduced enzymatic rates. The results reported here are of biological significance mainly because temperature and humidity are not uniform in stored grain products and may vary due to the presence of localized insect populations (Ernst and Mutchmor, 1969). In addition molds may raise the temperature of a stored grain pocket up to $60 \mathrm{C}$ and temperature gradients of $20 \mathrm{C} / \mathrm{m}$ are not uncommon (Surtees, 1964, 1965).

Niche structure usually is defined as a function of the overall tolerances of a life cycle. This study addresses the niche structure as a function of individual life cycle processes and reveals restrictions that are not apparent when life cycle processes are considered in combination over different life cycle stages. For example, MacDougall (1942) experimentally determined that the lethal temperature threshold for the oocysts of $G$. polymorpha was in the range of 60-64 C (some oocyst survival was observed at temperatures as high as $96 \mathrm{C}$ ). But, the extent to which the temperature tolerance of G. polymorpha oocysts affects the dispersal and transmission of the parasite in the host environment is mediated directly by the survival and developmental requirements of the gametocyst.

Host specificity has been discussed frequently as an ecological, largely host-mediated, phenom- enon (Holmes, 1976, 1979, 1990; Freeland, 1983; Aho, 1990). Interactions between infective stages and their environments and the overlap of infective stages and host feeding ranges have been recognized as factors that restrict host utilization (e.g., Kennedy, 1975). Although adult and larval $T$. molitor appear to occupy different physical strata in a laboratory colony, interspecific differences in host utilization by $G$. niphandrodes, $G$. cuneata, and $G$. polymorpha do not appear to be a result of nonoverlapping host distributions or competitive exclusion. Evidence presented by Clopton et al. (1992) indicates that host stadium specificity is not a function of host escape in time or space, but of interaction at the host-parasite interface. Observed differences in the life history and site specificity of the endogenous stages of G. cuneata and G. polymorpha indicate no competition between these species (Ruhnke and Janovy, 1990a, 1990b).

Gregarine development niches reflect the niche spaces of host stadia. The congruence of exogenous and endogenous restrictions suggests that these development niches are representative of adaptation or historical constraint that may have played a role in the colonization of the parasites' respective host stadia; historical host-capture events may have been mediated by overlap of the host niche and the exogenous development niche of the parasite. The existence of survival conditions that extend far beyond sporulation conditions suggests the importance of the gametocyst wall in gregarine radiation. The gametocyst wall is a phenotypic character that is continually tested against the environment. Changes in the humidity and temperature tolerances of the gametocyst wall have the potential to alter the development niche of a gregarine radically and subsequently to alter niche overlap with potential host stadia or species.

The observed nature of life history variation in the gregarine assemblage parasitizing $T$. molitor, as partitioned among host stadia, may be a result of host capture (Chabaud, 1981) or coaccommodation (Brooks, 1979); however, the relative evolutionary importance of the exogenous and endogenous life cycle stages in the rise of specificity is unclear. Based on the data presented here and by Clopton et al. (1992), we hypothesize that, at least in the case of the gregarine assemblage parasitizing $T$. molitor, host stadium specificity is a historical restriction. The inability of the members of the $T$. molitor gregarine complex to establish when artificially introduced in a het- 
erologous host stadium suggests that adaptation of the host-parasite interface enforces endogenous host stadium specificity. Interspecific differences in developmental niche structure suggest that cooccurrence of exogenous parasitic stages and their associated host stadia is mediated by the environmental tolerances of the gregarine gametocyst.

\section{ACKNOWLEDGMENTS}

This work was funded in part by the Ashton C. Cuckler and U. S. Harkson Fellowships awarded to R.E.C.

\section{LITERATURE CITED}

Aно, J. M. 1990. Helminth communities of amphibians and reptiles: Comparative approaches to understanding patterns and processes. In Parasite communities: Patterns and processes, G. Esch, A. Bush, and J. Aho (eds.). Chapman and Hall, New York, New York, p. 157-195.

Allegre, C. F. 1948. Contributions to the life history of a gregarine parasitic in grasshoppers. Transactions of the American Microscopical Society 67: 211-228.

ANONYMOUS. 1986. Pressure of aqueous vapor. In CRC handbook of chemistry and physics, R. C. Weast, M. J. Astle, and W. H. Beyer (eds.). CRC Press Inc., Boca Raton, Florida, p. D189-D191.

BRooks, D. R. 1979. Testing the context and extent of host-parasite co-evolution. Systematic Zoology 28: 299-307.

Buxton, P. A. 1930. Evaporation from the mealworm (Tenebrio: Coleoptera) and atmospheric humidity. Proceedings of the Royal Society of London, Series B 106: 560-577.

- 1932. Terrestrial insects and the humidity of the environment. Biological Review and Biological Proceedings of the Cambridge Philosophical Society 7: 275-320.

Chabaud, A. G. 1981. Host range and evolution of nematode parasites of vertebrates. In Evolution of helminths (Workshop 13, Third European Multicolloquium of Parasitology), D. W. T. Crompton (ed.). Parasitology 82: 169-174.

Clopton, R. E., T. J. Percival, and J. Janovy, JR. 1991. Gregarina niphandrodes, n. sp. (Apicomplexa: Eugregarinorida) from adult Tenebrio molitor $(\mathrm{L}$.) with oocyst descriptions of other gregarine parasites of the yellow mealworm. Journal of Protozoology 38: 472-479.

— - , AND - 1992. Host stadium specificity in the gregarine assemblage parasitizing Tenebrio molitor. Journal of Parasitology 78: 334337.

ERnst, S. A., AND J. A. Mutchmor. 1969. Dispersal of three species of grain beetles as a function of thermal acclimation, temperature, and larval size. Journal of Stored Products Research 5: 407-412.

Ferro, D. N., AND R. B. Chapman. 1979. Effects of different constant humidities and temperatures on two-spotted spider mite egg hatch. Environmental Entomology 8: 701-705.
Freeland, W. J. 1983. Parasites and the coexistence of animal host species. American Naturalist 121: 223-236.

Holmes, J. C. 1976. Host selection and its consequences. In Ecological aspects of parasitology, C. R. Kennedy (ed.). North-Holland Publishing Company, Amsterdam, The Netherlands, p. 2139.

. 1979. Population regulation and parasite flow through communities. In Host-parasite interfaces, B. B. Nickol (ed.). Academic Press, New York, New York, p. 27-46.

- 1990. Helminth communities in marine fishes. In Parasite communities: Patterns and processes, G. Esch, A. Bush, and J. Aho (eds.). Chapman and Hall, New York, New York, p. 101-130.

HowARD, R. S. 1955. The biology of the grain beetle Tenebrio molitor, with particular reference to its behavior. Ecology 26: 262-269.

KenNEDY, C. R. 1975. Ecological animal parasitology. Blackwell Scientific Publications, Oxford, U.K., 163 p.

LEVINE, N. D. 1979. New genera and higher taxa of sepatate gregarines (Protozoa, Apicomplexa). Journal of Protozoology 26: 532-536.

- 1985. Phylum II. Apicomplexa, 1970. In Illustrated guide to the protozoa, J. J. Lee, S. H. Hunter, and E. C. Bovee (eds.). Society of Protozoologists, Lawrence, Kansas, p. 322-374.

LIPA, J. J. 1967. Studies on gregarines (Gregarinomorpha) of arthropods in Poland. Acta Protozoologica 5: 1-179.

MacDougall, M. M. 1942. A study of the temperature effects on gregarines of Tenebrio molitor larvae. Journal of Parasitology 27: 233-240.

MACKINNON, D. L., AND R. S. J. HAwes. 1961. An introduction to the study of Protozoa. Oxford University Press, London, U.K., 506 p.

Mellanby, K. 1932. The influence of atmospheric humidity on the thermal death point of a number of insects. Journal of Experimental Biology 9: 141146.

Patil, C. C., S. D. Amoji, AND Y. F. Neelgund. 1983. Effect of temperature on the formation of gregarine sporocysts and their viability. Archiv für Protistenkunde 127: 181-187.

,-- AND -1985 . Studies on cross infection of cephaline gregarines of tenebrionid insects. Archiv für Protistenkunde 129: 179-182.

Perring, T. M., T. O. Holtzer, J. L. Toole, J. M. Norman, AND G. L. MEYers. 1984. Influences of temperature and humidity on pre-adult development of the Banks grass mite (Acari: Tetranychidae). Environmental Entomology 13: 338343.

Pielou, D. P., AND D. L. GunN. 1940. The humidity behaviour of the mealworm beetle, Tenebrio molitor L. I. The reaction to differences of humidity. Journal of Experimental Biology 17: 286-294.

Platt, R. B., AND J. F. GRIFFIThS. 1964. Environmental measurement and interpretation. Reinhold Publishing Company, New York, New York, 235 p.

Punzo, F., AND G. HufF. 1989. Comparative temperature and water relations and the effects of thermal acclimation on Tenebrio molitor and Tenebrio 
obscurus (Coleoptera: Tenebrionidae). Comparative Biochemistry and Physiology A. Comparative Physiology 93: 527-533.

, AND J. A. Mutchmor. 1978. Changes in temperature tolerance as a function of relative humidity during the larval stage of Tenebrio molitor (Coleoptera: Tenebrionidae). Journal of the Kansas Entomological Society 51: 207-212.

—, AND - 1 1980. Effects of temperature, relative humidity and period of exposure on the survival capacity of Tenebrio molitor (Coleoptera: Tenebrionidae). Journal of the Kansas Entomological Society 53: 260-270.

ReicheNOW, E., AND G. WÜLKER. 1929. Leitfaden zur Untersuchung der tierischen Parasiten des Menschen und der Haustiere. Curt Kabitzsch, Leipzig, Germany, 235 p.
RuHNKE, T. R., AND J. JANOVY, JR. 1990a. Life history differences between two species of Gregarina in Tenebrio molitor larvae. Journal of Parasitology 76: 222-240.

, AND - 1990b. The site specificity of two species of Gregarina in Tenebrio molitor larvae. Journal of Protozoology 36: 428-430.

SURTEES, G. 1964. Laboratory studies on dispersion behaviour of adult beetles in grain-I. The grain weevil, Sitophilus granarius (L.) (Coleoptera, Curculionidae). Bulletin of Entomological Research 54: $147-157$.

. 1965. Ecological significance and practical implications of behaviour patterns determining the spatial structure of insect populations in stored grain. Bulletin of Entomological Research 56: 201211 . 